University of Nebraska - Lincoln DigitalCommons@University of Nebraska - Lincoln

Chemical and Biomolecular Engineering -- All Chemical and Biomolecular Engineering, Faculty Papers

Department of

5-29-2019

\title{
Quantitative Electrochemical DNA Microarray on a Monolith Electrode with Ten Attomolar Sensitivity, 100\% Specificity, and Zero Background
}

Shobana Raghunath

Abhijeet Prasad

Rahul Tevatia

Jillian R. Gunther

Santanu Roy

See next page for additional authors

Follow this and additional works at: https://digitalcommons.unl.edu/chemengall

This Article is brought to you for free and open access by the Chemical and Biomolecular Engineering, Department of at DigitalCommons@University of Nebraska - Lincoln. It has been accepted for inclusion in Chemical and Biomolecular Engineering -- All Faculty Papers by an authorized administrator of DigitalCommons@University of Nebraska - Lincoln. 
Authors

Shobana Raghunath, Abhijeet Prasad, Rahul Tevatia, Jillian R. Gunther, Santanu Roy, Sunil Krishnan, and Ravi Saraf 
Published in final edited form as:

ChemElectroChem. 2018 February 1; 5(3): 429-433. doi:10.1002/celc.201700983.

(c) 2018 Wiley-VCH Verlag GmbH \& Co. KGaA, Weinheim

\title{
Quantitative Electrochemical DNA Microarray on a Monolith Electrode with Ten Attomolar Sensitivity, 100\% Specificity, and Zero Background
}

\author{
Shobana Raghunath ${ }^{\mathrm{a}}$, Abhijeet Prasad ${ }^{\mathrm{a}, \mathrm{b}}$, Rahul Tevatia ${ }^{\mathrm{b}}$, Jillian.R. Gunther ${ }^{\mathrm{c}}$, Santanu \\ Roya $^{a}$, Sunil Krishnan ${ }^{c}$, and Ravi F. Saraf ${ }^{b}$ \\ [a]Vajra Instruments, Inc.Lincoln, NE 68512 USA \\ ${ }^{[b]}$ Chemical Engineering, University of Nebraska Lincoln, NE 68588 USA \\ ${ }^{[c]}$ MD Anderson Cancer Research Center Houston, TX 77030 USA
}

\begin{abstract}
Circulating microRNA are promising diagnostic and prognostic biomarkers of disease in quantitative blood tests. A label-free, PCR-free, electrochemical microarray technology on a monolith electrode is described, with 10 attomolar (aM) sensitivity and responsiveness to binding of $<1$ zeptomole of target to immobilized ssDNA probes with zero background. Specificity is $100 \%$ in a mixture with five nonspecific miRNA each with a $10^{3}$-fold higher concentration. Direct measurement on plasma-derived miRNA without cDNA conversion and PCR demonstrated multiplexing and near-ideal quantitative correlation with an equivalent pure sample. The dynamic range is a target concentration ranging from $10^{-2}$ to $10^{3}$ femtomolar (fM). This PCR-free novel technology can be applied as a test for cancer diagnosis/prognosis to detect $10^{3}$ copies of a miRNA sequence in RNA extracted from $100 \mu \mathrm{L}$ of plasma.
\end{abstract}

\section{Keywords}

microarray; DNA sequencing; microRNA; cancer diagnosis; blood test; electrochemical analysis

Cell-derived circulating microRNA (miRNA) in blood, urine, and saliva could be utilized to develop a blood test for the diagnosis of diseases and for personalized therapy. It was recently discovered that most circulating miRNAs in blood are cell free and are remarkably stable in body fluids because of complexation with argonaute proteins, ${ }^{[1]}$ making them attractive for screening and early detection of diseases, particularly cancer. ${ }^{[2,3]}$ MiRNAs are noncoding 22 nucleotide (nt) long, single-stranded RNA (ssRNA) sequences that bind to mRNA by their 5'-seed region (2-8 nt long) to negatively regulate mRNA expression. ${ }^{[4]}$ MiRNAs regulate $\sim 60 \%$ of genes involved in a range of cellular activities, such as cell cycle, proliferation, differentiation, metabolism, inflammation, and immune response. ${ }^{[5,6]}$ As one

rsaraf2@unl.edu.

Conflict of Interest

The authors declare no conflict of interest.

Supporting information for this article is available on the WWW under https://doi.org/10.1002/celc.201700983 
miRNA can regulate multiple mRNAs and multiple miRNAs can regulate a single mRNA, ${ }^{[7]}$ a panel of miRNA is required to diagnose cancer at high specificity. ${ }^{[8]}$ Meta-analyses for a variety of cancers, for example, colorectal, ${ }^{[9]}$ lung, ${ }^{[10]}$ and pancreatic ${ }^{[11]}$ cancer, suggest that profiling dysregulation of several miRNA sequences can lead to diagnosis at over $85 \%$ sensitivity and specificity. Thus, the challenge in developing a screening test is to quantitatively profile a panel of miRNA sequences with proper controls ${ }^{[12]}$ at a sensitivity of $\sim 10$ copies in RNA extracted from a $1 / 4 \mathrm{~L}$ of blood ${ }^{[13]}$ over a dynamic range of five orders. ${ }^{[14]}$

The small size of miRNAs (unfortunately) leads to large variations in melting temperature due to small differences in sequence, making it difficult to multiplex a large number of sequences using qPCR, the gold standard ${ }^{[15]}$ Furthermore, synthesis of cDNA from miRNA by reverse transcriptase (RT) requires $\sim 10^{5}$ copies for efficient conversion. ${ }^{[16,17]}$ Hence, RNA from $\sim 10 \mathrm{~mL}$ of plasma is required to detect 10 copies in extracted RNA. To avoid PCR, several approaches have been developed to obtain a limit of detection (LOD) in the fM to aM range: the nanopore translocation method, ${ }^{[18]}$ an electrochemical transistor made from nanowires, ${ }^{[19]}$ surface plasmon resonance in nanoprisms, ${ }^{[20]}$ and differential pulse voltammetry from nanoelectrodes, ${ }^{[21]}$ which have reported LODs of $100 \mathrm{fM}, 1 \mathrm{fM}, \sim 40 \mathrm{aM}$, and $100 \mathrm{aM}$, respectively. A chip with a nano-electrode array has been shown to directly measure multiple miRNA sequences from plasma without the cDNA conversion and PCR. ${ }^{[22]}$ The analysis is usually non-absolute, requiring a difference in signals before and after the binding between the probe and the target miRNA, ${ }^{[19-22]}$ which may amplify error. Individual drops on each microspot need to be placed to confine the diffusion length, $[19,21,22]$ which may limit the device density and result in possible error due to solvent evaporation.

In this study, an electrochemical microarray patterned on a monolith electrode was developed resulting in robust statistics. To gain high sensitivity, a method was developed to focus $\sim 1,800$ molecules to microarray spots from $\sim 0.3 \mathrm{~mL}$ solution and measure $<1$ zeptomole target-to-probe binding. The combination allowed the technology to obtain sensitivity of 10 attomolar (i.e., $\sim 0.15 \mathrm{fg} / 1 / 4 \mathrm{~L}$ ) with $100 \%$ specificity over a dynamic range of five orders of magnitude. The unique feature not shown before is absolute signal with zero background, i.e., the signal for no binding is zero (which was confirmed for every chip).

For the study, using a 1.2 by $1.2 \mathrm{~cm}$ chip with five longer and two shorter (control) electrodes, an array of seven and three 50-1/4m holes (i.e., spots) were patterned on a photoresist, respectively, using photolithography (see Figure 1a and Sections S.1 and S.2 of the Supporting Information (SI) for details). Single-stranded DNA (ssDNA) probes with thio-terminated sequences were immobilized on the spots of an exposed Au electrode (Section S.3). The binding was performed in a solution of target molecules in $100 \mathrm{mM}$ of phosphate buffer $(\mathrm{PB})$ with $50 \mathrm{mM}$ of auxiliary ion $\left[\mathrm{Fe}(\mathrm{CN})_{6}\right]^{4-}$ by cyclic voltammetry $(\mathrm{CV})$ (Figure $1 \mathrm{~b}$ ). The $\mathrm{CV}$ ramp potential (V) applied between the working electrode (WE) and the reference electrode (RE) was from -0.4 to $0.3 \mathrm{~V}$ at a ramp rate of $50 \mathrm{mV} / \mathrm{s}$. The amount of binding on each of the five electrodes was controlled by the number of cycles, $\mathrm{N}$. Importantly, although the electric-field-influenced binding has been demonstrated before, ${ }^{[23]}$ the novelty here is the significant enhancement in binding due to the inclusion of redox ion, $\left[\mathrm{Fe}(\mathrm{CN})_{6}\right]^{4-}$. As the positive potential attracts the negatively charged target molecules, 
beyond $+220 \mathrm{mV},\left[\mathrm{Fe}(\mathrm{CN})_{6}\right]^{4-}$ oxidizes to $\left[\mathrm{Fe}(\mathrm{CN})_{6}\right]^{3-}$ causing the EDL to discharge to enhance the electric field penetration from $10^{2} \mathrm{~nm}$ (at no redox) to typically $10^{0} 1 / 4 \mathrm{~m}$ (during redox reaction). ${ }^{[24,25]}$ The deeper penetration of the electric field is independently shown by differential interferometry where the ion oscillation was significantly enhanced, leading to a peak at $\mathrm{V}$ close to redox. ${ }^{[25,26]}$ The binding process is called electrochemical redox enhanced binding (EREB). The effect of $\left[\mathrm{Fe}(\mathrm{CN})_{6}\right]^{4-}$ on binding efficiency is discussed later. Subsequent to vigorous washing, the uncovered area of the electrode was coated with a monolayer of mercaptohexanol (MCH) at $37^{\circ} \mathrm{C}$ (SI, Sections S.1 and S.4).

Binding of targets to an array of probes on a monolith electrode was measured electrochemically by scanning a laser. It is known that methylene blue (MB) undergoes redox by specifically binding to the probe-target duplex by electron transport through $\pi-\pi$ stacked base pairs. ${ }^{[27]}$ A differential reflectometer was designed and developed to measure local redox of MB on each microarray spot on the electrode (Figure 1c). Reflectivity measurements were performed in $100 \mathrm{mM}$ of $\mathrm{PB}$ containing $10^{1 / 4 \mathrm{M}}$ of $\mathrm{MB}$ and $50 \mathrm{mM}$ of $\left[\mathrm{Fe}(\mathrm{CN})_{6}\right]^{4-}$. The latter is the mediator for MB redox. ${ }^{[27]}$ The reflectivity was performed during $\mathrm{CV}$ with a potential (E) from -0.5 to $0.1 \mathrm{~V}$ to cover the redox of $\mathrm{MB}$ (at $\sim-0.2 \mathrm{~V}$ ). To measure differential reflectivity, a periodic AC potential of frequency, $\omega=2 \mathrm{KHz}$, and an amplitude of $100 \mathrm{mV}$ was added to the $\mathrm{CV}$ ramp. The detector measured a DC signal corresponding to incident intensity, $\mathrm{R}_{\mathrm{O}}$, and an $\mathrm{AC}$ signal at $\omega$ due to oscillation in the reflected light intensity caused by the oscillation of the ions due to the AC potential at $\omega$ (see SI, Section S.5 for the mechanism). The amplitude of the AC signal, $R_{A}$, was obtained from the lock-in amplifier tuned to $\omega$ to measure differential reflectivity, $R=R_{A} / R_{O}$, as low as $0.001 \%$.

Typical raw data on a spot with ssDNA probe, P155, that specifically binds to target T155 (ssDNA equivalent of miR155), showed oxidation and reduction peaks for MB (Figure 1d). The peaks were because the ion oscillation was maximum for $\mathrm{E}$ at maximum redox currents owing to deeper penetration of the electric field into the solution caused by discharge of the EDL. ${ }^{[25,26]}$ As R corresponds to charge at the interface, the reflectometer is called a scanning electrometer for electrical double layer (SEED). Superposing the various cycles of $\mathrm{R}(\mathrm{t})$ and filtering the high frequency noise, the average reflectivity, $\langle\mathrm{R}\rangle(\mathrm{E})$, was obtained from $\sim 20$ cycles (Figure 1e and Figure S5 in SI). The small error halo indicated that the oscillation of $\mathrm{R}$ was highly periodic leading to statistically robust $R_{\max }$. As the signal is a reduction of $\mathrm{MB}, R_{\max }$ is defined with respect to the reduction peak. The signal has a baseline because of ubiquitous oscillation of the ions due to AC potential at $2 \mathrm{KHz}$ at all potentials, E, related to the optical properties of the solution (see SI, Equation (4)). All subsequent data presented is after baseline subtraction on the reduction peak. Importantly, on the same electrode, the spot with a nonspecific probe (i.e., P21) showed no MB redox peak. Thus, the specificity from differential reflectivity was $100 \%$. The specificity was confirmed for each electrode on the chip. Specificity in a more aggressive environment is described in Figure 3.

The control electrode incorporated in every chip is an important unique feature of this method. No potential was applied during EREB on the shorter control electrodes. Each control electrode had a blank (i.e., bare Au) spot and one spot each with immobilized P155 
and P21. All spots were covered with an MCH monolayer after EREB. For good quality data, all of the six spots on the two control electrodes should show no redox. A signal on the blank spot indicates poor MCH filling which would lead to poor specificity where the signal could erroneously estimate target copies by as high as 3-fold (SI, Section S.6). Importantly, the spots with P155 and P21 probes on the control electrode should show no redox indicating that the signal is zero, if no binding occurs (i.e., ssDNA in Figure 1e). Thus, the $\mathrm{R}_{\max }$ reported will be an absolute measurement of the amount of specific binding. The absolute nature of the signal ensured for every chip is a unique feature of the method not reported before.

At constant, $\mathrm{N}$, as expected, $\mathrm{E}$ versus $\langle\mathrm{R}>($ at $\mathrm{N}=20$ ) showed a monotonic decrease in the overall signal as the concentration decreased from $1 \mathrm{pM}$ to $0.1 \mathrm{fM}$ (Figure 2a). By increasing $\mathrm{N}$ from 20 to 32 cycles, the binding increased significantly to observe a signal from a target concentration of $0.01 \mathrm{fM}$ (Figure 2a). $\mathrm{R}_{\max }$ at constant $\mathrm{N}(=20)$ increased linearly (at a fitness of $97 \%$ ) with a target concentration on a logarithmic scale of over four orders of magnitude (Figure 2b). Each $R_{\max }$ in the calibration curve for $\mathrm{N}=20$ and 32 (Figure $2 b$ )

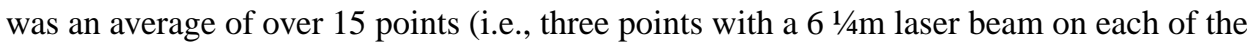
five $501 / 4 \mathrm{~m}$ spots on the electrode). Thus, five target concentrations were measured on each chip. The error bar was the standard deviation. The small error bar indicated excellent uniformity of immobilization, and reproduce bility of the measurement. Extrapolation to $R_{\max }=0$ (Figure 2b) indicated that the LOD for $N=20$ and 32 was $\sim 16$ aM and $3.9 \mathrm{aM,}$ respectively. The practical sensitivity for the study was $10 \mathrm{aM}$ or $0.15 \mathrm{fg} / 1 / 4 \mathrm{~L}$. For $0.3 \mathrm{~mL}$ solution during EREB, $10 \mathrm{aM}$ corresponded to $\sim 1,800$ molecules. Uniform binding of over five array spots, implied that SEED can detect binding of $<360$ target molecules, i.e., a responsivity of $<1$ zeptomole.

Using SEED, the nature of the EREB process was characterized. Due to the increase in a larger penetration depth due to oxidation of $\left[\mathrm{Fe}(\mathrm{CN})_{6}\right]^{4-}$ noted above, the $\mathrm{R}_{\max }$ increased from $\sim 0.3 \times 10^{-4}$ to $1.3 \times 10^{-4}$ for $1 \mathrm{fM}$ of target due to the addition of $50 \mathrm{mM}\left[\mathrm{Fe}(\mathrm{CN})_{6}\right]^{4-}$ during the EREB process at $\mathrm{N}=32$ cycles (Figure 2c). Based on Figure 2a, this remarkable increase in $\mathrm{R}_{\max }$ by $1 \times 10^{-4}$ due to inclusion of $\left[\mathrm{Fe}(\mathrm{CN})_{6}\right]^{4-}$ was equivalent to an increase in target concentration by tenfold. As the $\mathrm{V}$ ramped to negative values, the loosely attached target molecules were repelled to reactivate the probes. The negative potential of $\mathrm{V}=-0.4 \mathrm{~V}$ was sufficient for efficient repulsion of the nonspecific target to obtain the observed $100 \%$ specificity.

Three types of samples were studied to evaluate multiplexing and specificity in complex systems. First, a synthetic mixture of miR155 (1 fM) and miR21(10fM) in a background of five miRNA each with a concentration of $1 \mathrm{pM}$ (sequences and more detail shown in SI, Section S.7) was analyzed on a chip at different N (Figure 3a). The $R_{\max }$ for T155 was consistent with values in Figure $2 \mathrm{~b}$, indicating no interference from the background. The $R_{\max }$ for $\mathrm{T} 21$ was higher than for $\mathrm{T} 155$ and was also consistent with a higher concentration. Thus, EREB/SEED can quantitatively measure multiple sequences in significantly larger background. 
Second, RNA was extracted from $2001 / 4 \mathrm{~L}$ of plasma from a healthy donor and spiked with C. elegans miR39a. After reconstituting the RNA in $3001 / 4 \mathrm{~L}$ of PB buffer, EREB was carried at $4^{\circ} \mathrm{C}$ to avoid RNA degradation. The $R_{\max }$ for miR39a in buffer (i.e., calibration curve) was measured (Figure $3 \mathrm{~b}$ ) and compared to $R_{\max }$ spiked in plasma for a concentration ranging from $10 \mathrm{aM}$ to $1 \mathrm{pM}$ (Figure $3 \mathrm{~b}$, inset). The correlation was remarkable, showing that the effect of background due to other molecules in plasma is negligible. Because it is possible to measure $\sim 200$ copies of target (i.e., $10 \mathrm{aM}$ in $300 \mathrm{1} / 4 \mathrm{~L}$ ) extracted from $2001 / 4 \mathrm{~L}$ of plasma, the method can safely measure $\sim 10^{3}$ copies of (specific) miRNA extracted from 100 $1 / 4 \mathrm{~L}$ of plasma at zero background.

Third, to demonstrate multiplexing and quantitative comparison to qPCR, RNA was extracted from the plasma of a colorectal cancer patient (CRC) and a normal donor (ND) and spiked with miR39 of $C$. elegans. The copy number of each miRNA was normalized with respect to $\mathrm{R}_{\max }$ for a miR39a spike in the extracted RNA (using the calibration curve for SEED (Figure 3)) and the standard qPCR curve (SI, Figure S8). In all cases, the dysregulation by SEED and qPCR was consistent; and the relative copy numbers were quantitatively comparable (Figure 3c). For miR34a, the values were in the opposite direction because the copy number was close to spiked miR39a; however, the magnitudes were comparable (see SI, Section S.8 and Table).

In summary, we report a novel technology to electrochemically measure binding on a microarray patterned on a monolith electrode. The sensitivity is $10 \mathrm{aM}$ (i.e., $\sim 0.15 \mathrm{fg} / 1 / 4 \mathrm{~L}$ ) with a limit of detection of $\sim 3.9 \mathrm{aM}$ at $100 \%$ specificity and a dynamic range of five orders of magnitude with robust statistics. By spiking plasma with miRNA, a direct analysis from extracted RNA without PCR and cDNA conversion was illustrated with remarkable correlation from $10 \mathrm{aM}$ to $1 \mathrm{pM}$ of spiked miR39a. Multiplexing on a single chip was demonstrated by directly measuring five miRNA plus one negative control for RNA extracted from $2001 / 4 \mathrm{~L}$ of plasma from a healthy donor and a cancer patient. The comparison to qPCR was quantitative for all of the miRNA targets. This label-free technology could be implemented as a tool for prognostic and diagnostic application.

\section{Supplementary Material}

Refer to Web version on PubMed Central for supplementary material.

\section{Acknowledgements}

R.F.S. thanks NIH/NCI (CA186788-01; CA199058-01) and Nebraska Department of Economic Development (1601-171; 15-01-055) for financial support.

\section{References}

[1]. Turchinovich A, Weiz L, Langheinz A, Burwinkel B, Nucleic Acids Res. 2011, 39,7223-7233. [PubMed: 21609964]

[2]. Nana-Sinkam SP, Croce CM, Clinical Pharmacology \& Therapeutics 2013, 93, 98-104. [PubMed: 23212103]

[3]. Reid G, Kirschner MB, van Zandwijk N, Critical Reviews in Oncology Hematology 2011, 80, 193-208. 
[4]. Bartel DP, Cell 2009, 136, 215-233. [PubMed: 19167326]

[5]. Ahmad J, Hasnain SE, Siddiqui MA, Ahamed M, Musarrat J, Al- Khedhairy AA, Indian J Med. Res. 2013, 137, 680-694.

[6]. Di Leva G, Garofalo M, Croce CM, MicroRNAs in Cancer 2014, pp. 287-314.

[7]. Lewis BP, Shih IH, Jones-Rhoades MW, Bartel DP, Burge CB, Cell 2003, 115, 787-798. [PubMed: 14697198]

[8]. Lan HY, Lu HQ, Wang X, Jin HC, BioMed Res. Int. 2015.

[9]. Kanaan Z, Roberts H, Eichenberger MR, Billeter A, Ocheretner G, Pan JM, Rai SN, Jorden J, Williford A, Galandiuk S, Ann. Surg. 2013, 258, 400-408. [PubMed: 24022433]

[10]. Vosa U, Vooder T, Kolde R, Vilo J, Metspalu A, Annilo T, Int. J. Cancer 2013, 132, 2884-2893. [PubMed: 23225545]

[11]. Pei ZL, Liu SM, Huang JT, Zhang X, Yan D, Xia QL, Ji CX, Chen WP, Zhang XY, Xu JQ, Wang J, Oncotarget 2017, 8, 22616-22624. [PubMed: 28186984]

[12]. Pritchard CC, Kroh E, Wood B, Arroyo JD, Dougherty KJ, Miyaji MM, Tait JF, Tewari M, Cancer Prev. Res. 2012, 5, 492-497.

[13]. Mitchell PS, Parkin RK, Kroh EM, Fritz BR, Wyman SK, Pogosova-Agadjanyan EL, Peterson A, Noteboom J, O’Briant KC, Allen A, Lin DW, Urban N, Drescher CW, Knudsen BS, Stirewalt DL, Gentleman R, Vessella RL, Nelson PS, Martin DB, Tewari M, Proc. Natl. Acad. Sci. USA 2008, 105, 10513-10518. [PubMed: 18663219]

[14]. Graybill RM, Bailey RC, Anal. Chem. 2016, 88, 431-450. [PubMed: 26654257]

[15]. Lee IH, Ajay SS, Chen HM, Maruyama A, Wang NL, Mclnnis MG, Athey BD, Nucleic Acids Res. 2008, 36 .

[16]. Miranda JA, Steward GF, Virol J. Methods 2017,241 1-10.

[17]. Zhao Q, Deng SQ, Wang GX, Liu CC, Meng LY, Qiao SS, Shen L, Zhang Y, Lu JH, Li WS, Zhang YZ, Wang M, Pestell RG, Liang CL, Yu ZR, Oncotarget 2016, 7, 21865-21874. [PubMed: 26967564]

[18]. Wang Y, Zheng DL, Tan QL, Wang MX, Gu LQ, Nat. Nanotechnol. 2011, 6, 668-674. [PubMed: 21892163]

[19]. Zhang GJ, Chua JH, Chee RE, Agarwal A, Wong SM, Biosens. Bioelectron. 2009, 24, 2504 2508. [PubMed: 19188058]

[20]. Joshi GK, itz-McElyea S, Liyanage T, Lawrence K, Mali S, Sardar R, Korc M, ACS Nano 2015, 9, 11075-11089. [PubMed: 26444644]

[21]. Yang H, Hui A, Pampalakis G, Soleymani L, Liu FF, Sargent EH, Kelley SO, Angewandte Chemie-International Edition 2009, 48, 8461-8464. [PubMed: 19810065]

[22]. Das J, Ivanov I, Montermini L, Rak J, Sargent EH, Kelley SO, Nat. Chem. 2015, 7, 569-575. [PubMed: 26100805]

[23]. Wong IY, Melosh NA, Nano Lett. 2009, 9, 3521-3526. [PubMed: 19606816]

[24]. Bard AJ, Faulkner LR, Electrochemical Methods: fundamentals and Applications, 2nd ed J. Wiley \& Sons, New York, 2001.

[25]. Lee SW, Lopez J, Saraf RF, Electroanalysis 2013, 25, 1557-1566.

[26]. Lee SW, Lopez J, Saraf RF, Biosens. Bioelectron. 2013, 47, 408-414. [PubMed: 23612062]

[27]. Drummond TG, Hill MG, Barton JK, Nat. Biotechnol. 2003, 21, 1192-1199. [PubMed: 14520405] 

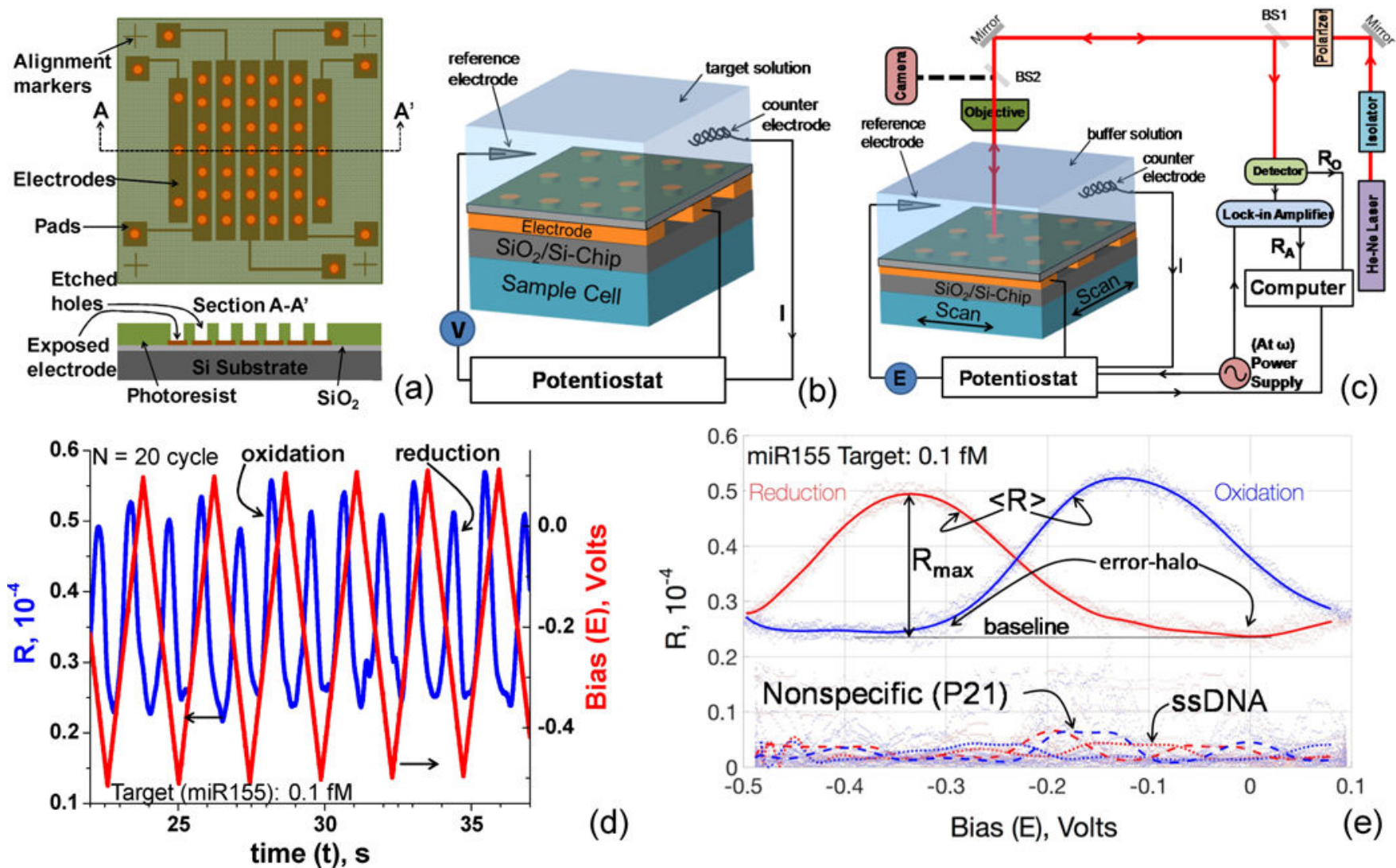

Figure 1.

a) The electrodes and circuitry are on an approximately $200 \mathrm{~nm}$ thick $\mathrm{SiO}_{2}$ layer on $\mathrm{Si}$. The etched photoresist (SU8) exposes the underlying electrode (cross-section A-A', not to scale). The shorter electrodes are controls, where no EREB potential is applied. b) The EREB setup is a three-electrode system controlled by a potentiostat (AutoLab PGSTAT302 $\mathrm{N}$ ). The $\mathrm{RE}$ and $\mathrm{CE}$ are $\mathrm{Ag} / \mathrm{AgCl}$ and $\mathrm{Pt}$ wire, respectively. A potential, $V$, is applied between the chip electrode (WE) and RE; and current, $I$, is measured between the WE and the CE. c) The differential reflectivity is measured during CV. As the potential, $E$, is ramped between the WE and the RE, the modulation in reflected light intensity, $R_{\mathrm{A}}$, at $\omega$ is amplified by the lock-in amplifier. The incident light intensity, $R_{\mathrm{O}}$ measured as a DC signal. d) Raw data: $R$ and $E$ as a function of time, $t$ (for specific binding); the full scan is shown in Figure S5. e) E versus $R$ with "error halo" corresponding to cycle-to-cycle variations. The ssDNA is $R$ from a spot with P155 on the control electrode not subjected to EREB. The nonspecific spot corresponds to the spot with P21 on the same electrode as the specific spots. $R_{\max }$ is defined for the reduction peak with respect to the baseline. 

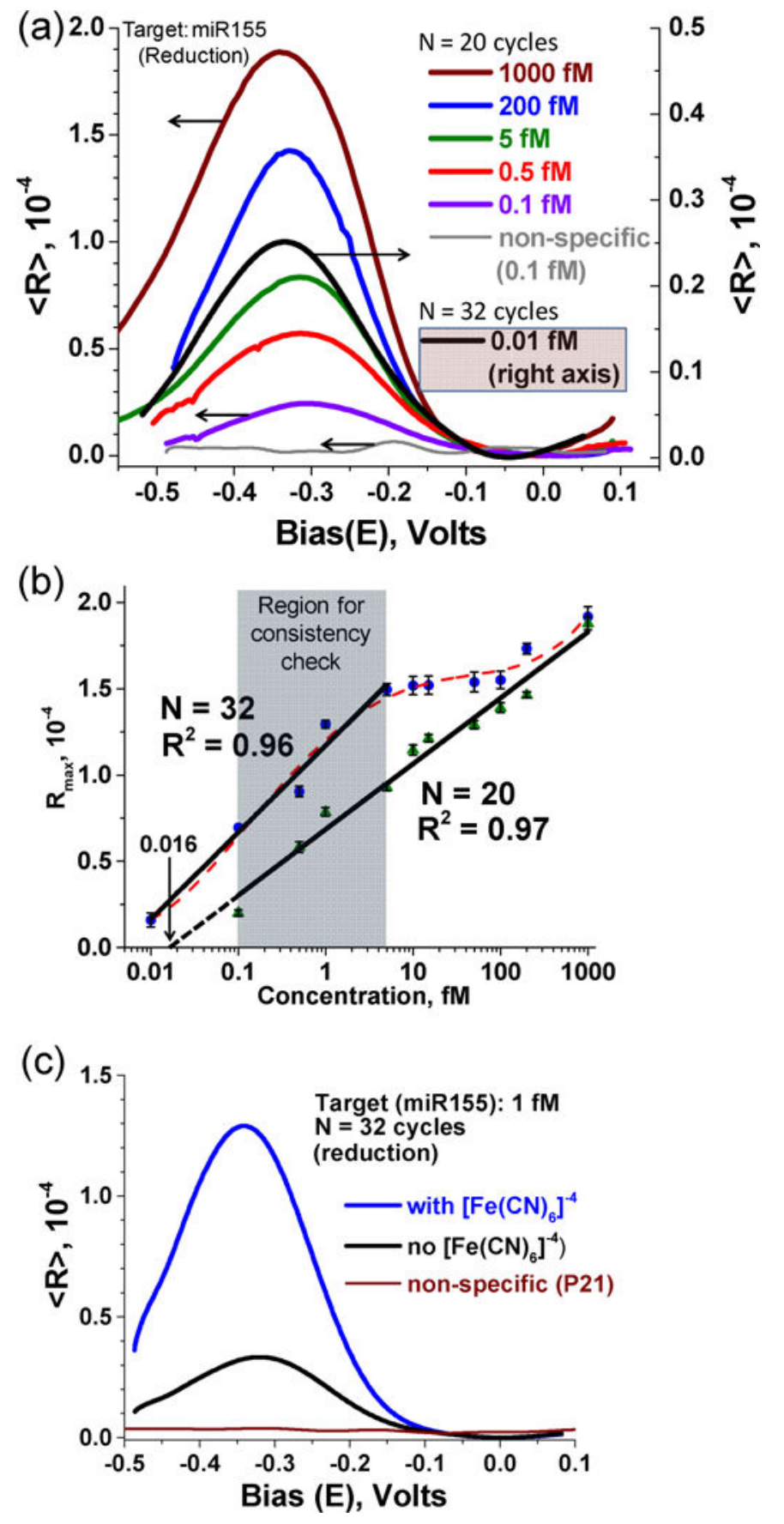

Figure 2.

a) Typical baseline-corrected $E$ versus $\langle\mathrm{R}\rangle$ for various miR 155 target concentrations on the spot with P155 for EREB performed at $N=20$. The LOD was $0.01 \mathrm{fM}$ at $N=32$ (right axis). b) $R_{\max }$ as a function of target concentration. Each data point was averaged over $15 E$ versus $\langle\mathrm{R}\rangle$ scans. All of the controls and the nonspecific spot had zero signals. c) Effect of auxiliary ions on reflectivity was measured on the same spot without removing the chip from the sample chamber. First the experiment with no $\left[\mathrm{Fe}(\mathrm{CN})_{6}\right]^{4-}$ (in PB buffer) was conducted, 
followed by a vigorous wash with distill water before the second experiment containing $\left[\mathrm{Fe}(\mathrm{CN})_{6}\right]^{4-}$ in PB buffer. 

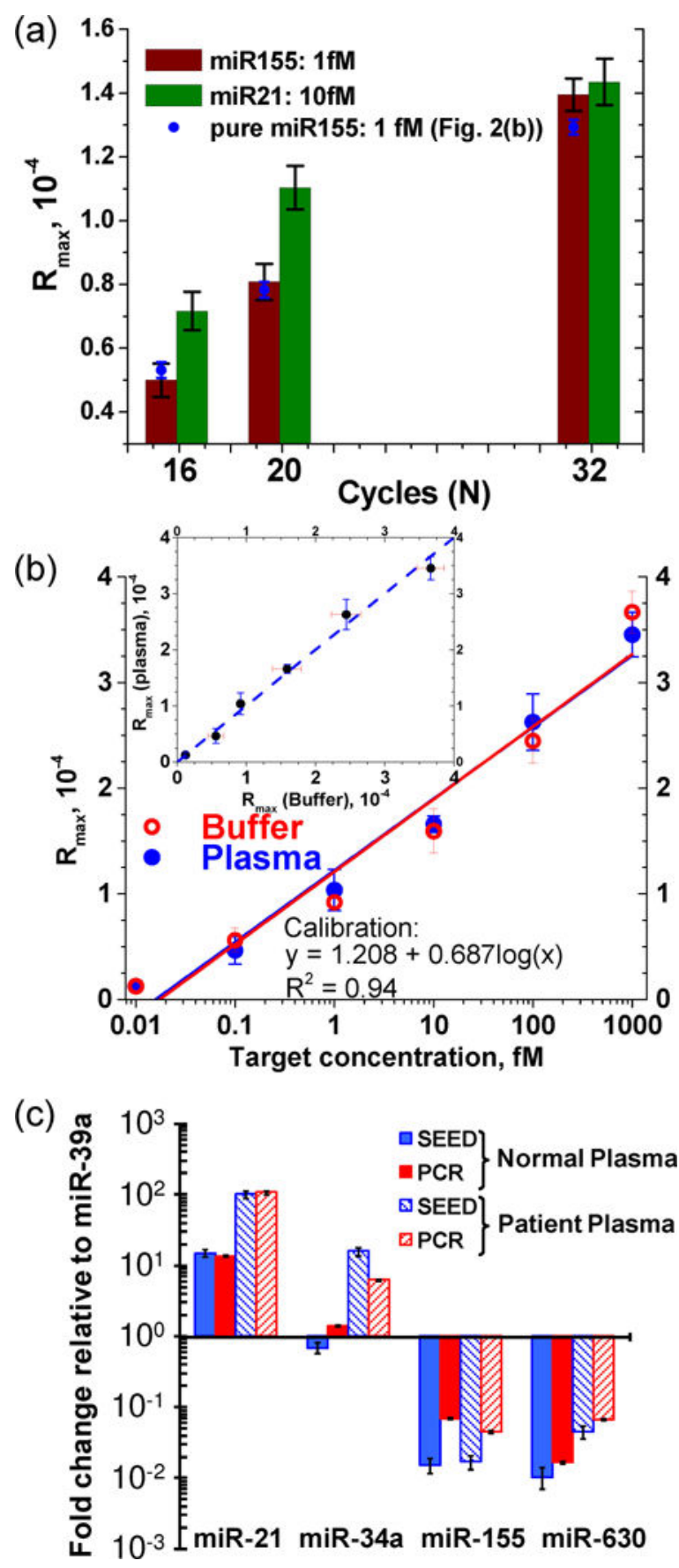

Figure 3.

a) The $R_{\max }$ on a chip for specific binding of miR155 and miR21 with five background miRNA each at $1 \mathrm{pM}$ concentration. b) Comparison of $R_{\max }$ for miR39a in standard EREB buffer and spiked in extracted RNA from plasma and reconstituted in identical buffer (plasma). Inset: Comparison of signal from pure and plasma samples with a miR39a concentration ranging from 0.01 to $10^{3} \mathrm{fM}$. c) Comparison of patient and healthy plasma for four miRNA by qPCR and SEED (on a single chip). 


\section{Supporting Information (SI)}

\section{S.1 Overall summary of all the steps used in the technology}

Further details on various steps described are in the various sections below.

Chip Fabrication: The microarray was made on a 1.2 by $1.2 \mathrm{~cm} \mathrm{Si} \mathrm{chip} \mathrm{with} \mathrm{Au}$ electrodes and accompanying circuitry for power and signal on $\sim 200 \mathrm{~nm} \mathrm{SiO}{ }_{2}$ to provide an insulating surface. (Fig. 1(a)). The chip was cleaned in acetone, water, and ethanol followed by $\mathrm{O}_{2}$ plasma and subsequently immersed in piranha solution for $\sim 60 \mathrm{sec}$. The chip was dried by blowing clean $\mathrm{N}_{2}$ from a $0.2 \mu \mathrm{m}$ filter. Photoresist SU8 (Microchem 2025) was diluted by adding three times the volume of cyclopentanone which was spin cast on the chip at 3,000 rpm for $60 \mathrm{sec}$. to produce an $\sim 500-\mathrm{nm}$ thick film. The chip was prebaked for $45 \mathrm{sec}$. at $80^{\circ} \mathrm{C}$. The film was exposed to Xe light ( $\left.300 \mathrm{~W}\right)$ for $45 \mathrm{sec}$. through a contact mask with a $\mathrm{Cr}$ metalized pattern on quartz. The chip was post-baked for $45 \mathrm{sec}$. at $80{ }^{\circ} \mathrm{C}$ and developed in Microchem SU8 developer. The chip was then washed with water/isopropanol for $\sim 60 \mathrm{sec}$ and hard baked at $140{ }^{\circ} \mathrm{C}$ for $2 \mathrm{hr}$. The resulting pattern on each electrode was a microarray of $50 \mu \mathrm{m}$ holes exposing the underlying Au electrode.

Probe Immobilization: The immobilization on the spots was obtained by locally dispensing $5 \mu \mathrm{M}$ solution of the probe in $1 \mathrm{M}$ of phosphate buffer (PB) using an rrrayit $^{\circledR}$ capillary pin with tip of $\sim 20 \mu \mathrm{m}$ (Fig. S2). The $5 \mathrm{~nL}$ solution dispensed on each spot was held by surface tension (Fig. S3). Each spot of the chip was exposed to the probe solution drop at $19{ }^{\circ} \mathrm{C}$ in a humidified chamber to avoid evaporation during the immobilization process for at least $16 \mathrm{hrs}$. The actual exposure was for only $2 \mathrm{hrs}$. The chip was washed and the process repeated again to obtain higher immobilization density. All of the solutions and the washing were performed using RNAse-free water (Invitrogen).

Electrochemical Redox-Enhanced Binding (EREB) Process: Subsequent to vigorous washing, EREB was performed in a (10 aM to $1 \mathrm{pM})$ solution of target molecules in $100 \mathrm{mM}$ of phosphate buffer $(\mathrm{PB})$ with $50 \mathrm{mM}$ of auxiliary ion $\left[\mathrm{Fe}(\mathrm{CN})_{6}\right]^{4-}$ by cyclic voltammetry (CV). The CV ramp potential $(\mathrm{V})$ applied between the working 
electrode (WE) and the reference electrode (RE) was from -0.4 to $0.3 \mathrm{~V}$ at a ramp rate of $50 \mathrm{mV} / \mathrm{s}$. As the positive potential attracts the negatively charged target molecules, beyond $+220 \mathrm{mV},\left[\mathrm{Fe}(\mathrm{CN})_{6}\right]^{4-}$ oxidizes to $\left[\mathrm{Fe}(\mathrm{CN})_{6}\right]^{3-}$ causing the $\mathrm{EDL}$ to discharge to enhance the electric field penetration from $10^{2} \mathrm{~nm}$ (at no redox) to typically $10^{\circ} \mu \mathrm{m}$ (during redox reaction). ${ }^{1,2}$ To note is that the electric-field-influenced binding has been demonstrated before. ${ }^{3}$ The novelty in this method is the significant enhancement in binding due to the inclusion of redox ion. The scanning range of EREB was optimized using SEED.

MCH Filling Process: The $\mathrm{MCH}$ coating was one of the critical aspects of the fabrication. The goal was to completely coat all of the exposed Au electrode surfaces after the the target binding step such that there was no signal on all of the three spots of the control electrode: the blank spot and the two spots with (immobilized) P155 and P21. The control electrode was not subjected to EREB, thus the spots had no binding. A signal on the control electrode would imply that the quality of $\mathrm{MCH}$ is poor and the signal on the active electrodes (that were subjected to EREB) is not absolute.

The $\mathrm{MCH}$ immobilization was performed in two steps. The chip was exposed to vapors from a $0.5 \mathrm{~mL}$ solution of $10 \mathrm{mM} \mathrm{MCH}$ in RNAse-free water (Invitrogen) at $37^{\circ} \mathrm{C}$ for $10 \mathrm{hr}$. The process is called atomic layer deposition (ALD). The chip was dry with no condensation of water during ALD. After rinsing in autoclaved DI water, the chip was then immersed in a $1 \mathrm{~mL}$ solution of $10 \mathrm{mM} \mathrm{MCH}$ in $30 \%$ HPLC grade ethanol for 3 hours with vigorous shaking at $100 \mathrm{rpm}$ in an incubator at $37^{\circ} \mathrm{C}$. The chip was subsequently rinsed and immersed in solution for differential reflectivity measurement. All of the solutions and washing/rinsing was performed in RNAse-free water (Invitrogen). MCH filling is after the EREB process to obtain good binding.

\section{Differential Reflectivity Measurements (Scanning Electrometer for Electrical} Double-layer (SEED)): Differential reflectivity was performed during CV with a potential $(E)$ from -0.5 to $0.1 \mathrm{~V}$ to cover the redox of $\mathrm{MB}$ (at $\sim-0.2 \mathrm{~V}$ ). A periodic $\mathrm{AC}$ potential of frequency, $\omega=2 \mathrm{kHz}$, and amplitude of $100 \mathrm{mV}$ were added to the CV ramp. The detector measured a $\mathrm{DC}$ signal corresponding to incident intensity, $R_{\mathrm{O}}$, and an $A C$ signal at $\omega$ due to oscillation in the reflected light intensity caused by the oscillation of the ions due to the AC potential at $\omega$. The amplitude of the $A C$ signal, $R_{A}$, was obtained from the lock-in amplifier tuned to $\omega$ to measure differential reflectivity, $R$ $=R_{A} / R_{O}$, as low as $0.001 \%$. The peaks were observed in Fig. 1(e) because the ion oscillation was maximum for $E$ at maximum redox currents owing to deeper penetration of the electric field into the solution. ${ }^{4}$

qPCR Analysis: Total RNA was extracted using a standard kit (RNeasy Plus kit from QIAGEN). The total RNA was converted to cDNA using First Strand Synthesis kit (Clontech Lab., Inc). SYBR ${ }^{\mathrm{TM}}$ Green method (Clontech Lab., Inc) was adopted to perform the cDNA synthesis and qPCR measurements on the qPCR machine 
(QuantStudio ${ }^{T \mathrm{~T}} 3 \mathrm{RT}-\mathrm{PCR}, \mathrm{ABI}, \mathrm{USA}$ ). Briefly, $3.75 \mu \mathrm{L}$ of a standard solution with known concentration was added to reverse transcriptase buffer and enzyme (the final reaction volume was $10 \mu \mathrm{L}$ ). The reaction was allowed to incubate at $37{ }^{\circ} \mathrm{C}$ for one hour, followed by denaturation of the RT enzyme at $85{ }^{\circ} \mathrm{C}$ for five minutes. The synthesized cDNA was diluted by 10 -fold. A $0.8 \mu \mathrm{L}$ portion was added to the master stock (SYBR Advantage Premix, ROX, miRNA-specific $5^{\prime}$ and $3^{\prime}$ primers) resulting in the final volume of $10 \mu \mathrm{L}$. Melting curves on qPCR products were also generated to confirm specificity of the amplification. After GPCR, the data was analyzed while setting the threshold fluorescence to 0.059 arbitrary units. The threshold was set to a constant for biological replicates. Based on $\mathrm{Ct}$ values, the relative fold change in targeted miRNAs was calculated. Quantification of miRNA copy number was calculated from standard curve. For the standard curve, at least $10^{6}$ copies are needed in the RT mix, consistent with the literature (see Fig. S9 in Section S.9). ${ }^{5}$

\section{S.2 Chip Fabrication}

The microarray was made on a 1.2 by $1.2 \mathrm{~cm}$ Si chip with $\mathrm{Au}$ electrodes and accompanying circuitry for power and signal (Fig. 1(a)). The chip is passivated with $\sim 200 \mathrm{~nm} \mathrm{SiO} 2$ to provide an insulating surface. The chip was coated with SU8 photoresist to make seven and three $50-\mu \mathrm{m}$ holes on the longer and shorter electrodes, respectively, using a standard photolithography process (Fig. S1). Briefly, the chip was cleaned in acetone, water, and ethanol followed by $\mathrm{O}_{2}$ plasma and subsequently immersed in piranha solution for $\sim 60 \mathrm{sec}$. The piranha solution was freshly prepared by mixing $\mathrm{H}_{2} \mathrm{SO}_{4}$ in $\mathrm{H}_{2} \mathrm{O}_{2}$ at a volume ratio of $3: 1$, respectively. The chip was dried by blowing clean $\mathrm{N}_{2}$ from a $0.2 \mu \mathrm{m}$ filter. Photoresist SU8 (Microchem 2025) was diluted by adding three times the volume of cyclopentanone which was spin cast on the chip at $3000 \mathrm{rpm}$ for $60 \mathrm{sec}$. to produce an $\sim 500-\mathrm{nm}$ thick film. The chip was prebaked for 45 sec. at $80^{\circ} \mathrm{C}$. The film was exposed to Xe light $(300 \mathrm{~W})$ for $45 \mathrm{sec}$. through a contact mask with a $\mathrm{Cr}$ metalized pattern on quartz. The chip was post-baked for $45 \mathrm{sec}$. at $80^{\circ} \mathrm{C}$ and developed in Microchem SU8 developer for $\sim 5$ min. with intermittent sonication for $20 \mathrm{sec}$ (three times in the process). The chip was then washed with water/isopropanol for $\sim 60 \mathrm{sec}$ and hard baked at $140{ }^{\circ} \mathrm{C}$ for $2 \mathrm{hr}$.

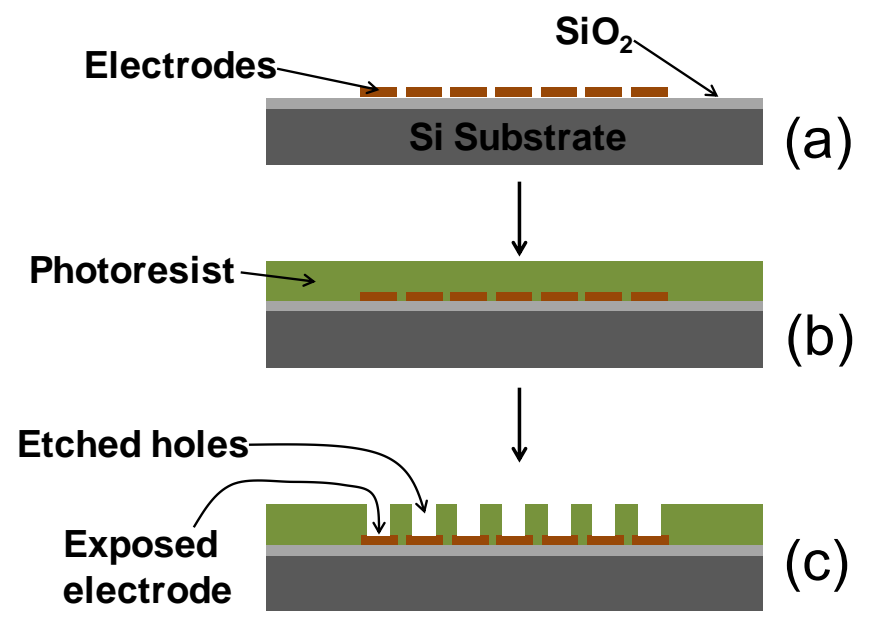

Figure S1: Cross-sectional view of the chip defined by $A-A^{\prime}$ in Fig. 1(a). Broadly, the photolithography had the following steps: (a) initial chip with electrodes; (b) after spin coating SU-8 photoresist; and (c) the chip after exposure to light and development to obtain a pattern of etched holes. 


\section{S.3 Probe Immobilization}

Two types of probes were utilized in the study:

- P155: 5'-HS- $\left(\mathrm{CH}_{2}\right)_{6}$-AAA- ACC CCT ATC ACG ATT AGC ATT AA 3'

- P21: 5'-HS-($\left(\mathrm{CH}_{2}\right)_{6}-\mathrm{AAA}-\mathrm{TCA}$ ACA TCA GTC TGA TAA GCT A-3'

The corresponding specific targets were:

- miR-155: 5' TTA ATG CTA ATC GTG ATA GGg GT 3'

- miR-21: 5' TAG CTT ATC AGA CTG ATG TTG A 3'

The immobilization on the spots was obtained by locally dispensing $5 \mu \mathrm{M}$ solution of the probe in $1 \mathrm{M}$ of phosphate buffer (PB) using an Arrayit ${ }^{\circledR}$ capillary pin (Fig. S2(a)). The capillary size of the pin was $\sim 20 \mu \mathrm{m}$ (Fig. S2(b), optical microscope image). The $5 \mathrm{~nL}$ solution dispensed on each spot was held by surface tension (Fig. S3). Each spot of the chip was exposed to the probe solution drop at $19{ }^{\circ} \mathrm{C}$ in a humidified chamber to avoid evaporation during the immobilization process for $2 \mathrm{hr}$. The chip was washed and the process repeated again to obtain higher immobilization density. All of the solutions and the washing were performed using RNAse-free water (Invitrogen).
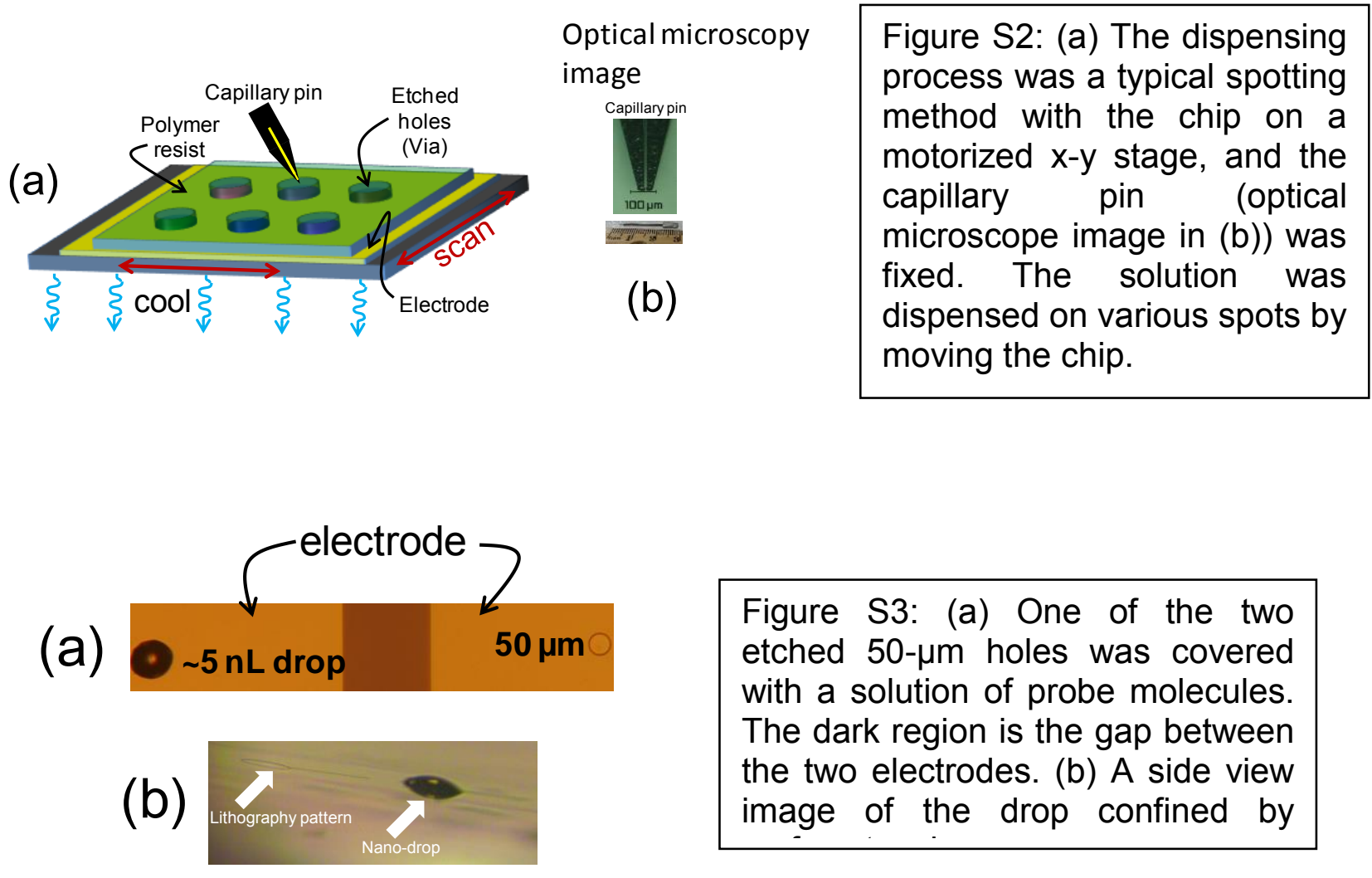

Figure S3: (a) One of the two etched $50-\mu \mathrm{m}$ holes was covered with a solution of probe molecules. The dark region is the gap between the two electrodes. (b) A side view image of the drop confined by 


\section{S.4 MCH Filling Process}

The $\mathrm{MCH}$ coating is one of the most critical aspects of the fabrication that decides the specificity and quality of measurement (see Section S.6 discussed later). The goal was to completely coat all of the exposed Au electrode surfaces after the the target binding step such that there was no signal on all of the three spots of the control electrode: the blank spot and the two spots with (immobilized) P155 and P21. The control electrode was not subjected to EFIB, thus the spots had no binding.

The $\mathrm{MCH}$ immobilization was performed in two steps. The chip was exposed to vapors from a $0.5 \mathrm{~mL}$ solution of $10 \mathrm{mM} \mathrm{MCH}$ in RNAse-free water (Invitrogen) at $37^{\circ} \mathrm{C}$ for $10 \mathrm{hr}$. The process is called atomic layer deposition (ALD). The chip was dry with no condensation of water during ALD. After rinsing in autoclaved DI water, the chip was immersed in $1 \mathrm{~mL}$ solution of $10 \mathrm{mM} \mathrm{MCH}$ in $30 \% \mathrm{HPLC}$ grade ethanol for 3 hours with vigorous shaking at $100 \mathrm{rpm}$ in an incubator at $37^{\circ} \mathrm{C}$. The chip was subsequently rinsed and immersed in solution for differential reflectivity measurement. All of the solutions and washing /rinsing was performed in RNAse-free water (Invitrogen).

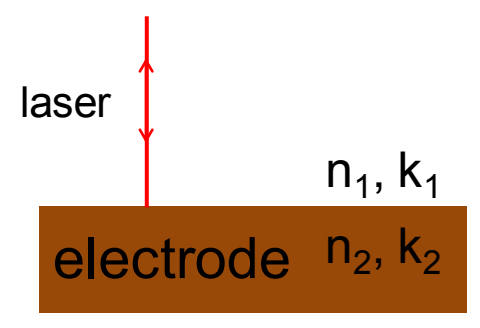

Figure S4: A schematic of the reflectivity kinematics defining the optical properties.

\section{S.5 Oscillation of Reflected Light}

Let $\left(n_{1}, k_{1}\right)$ and $\left(n_{2}, k_{2}\right)$ be the real and imaginary refractive index of the solution and electrode, respectively (Fig. S4), where $k_{i}=(\lambda / 4 \pi) \alpha_{i}$ (where $\alpha_{i}$ is the absorption coefficient of the material at wavelength, $\lambda$, of the incident light). In the most simplified case, it is assumed that there is no concentration gradient, thus $n_{1}$ is not a function of $x$. The assumption is not good; however, the analytical solution captures the principle of the measurement, i.e., the modulation of the reflectivity as average $n_{1}$ oscillates due to applied potential on the electrode. From Fresnel's law, the reflectivity, r, at normal incidence is,

$$
r=\frac{\left(n_{1}-n_{2}\right)-i\left(k_{1}-k_{2}\right)}{\left(n_{1}+n_{2}\right)-i\left(k_{1}+k_{2}\right)}
$$

Thus, the magnitude of reflectivity is,

$$
|r|^{2}=\left|\frac{\left\{\left(n_{1}^{2}-n_{2}^{2}\right)-\left(k_{1}^{2}-k_{2}^{2}\right)\right\}^{2}+4\left(n_{1} k_{1}-n_{2} k_{2}\right)^{2}}{\left\{\left(n_{1}+n_{2}\right)^{2}+\left(k_{1}+k_{2}\right)^{2}\right\}^{2}}\right|^{2}
$$


The refractive index is given by, $n_{1}=n_{w}+(d n / d c) c$, where $c$ is a concentration of various ions, $d n / d c$ is the corresponding differential refractive index, and $n_{w}$ is the refractive index of water. The details of the second term are not so critical, however, because the polarizability of the anion is larger than the cation, the refractive index modulation of the former will dominate over the latter. For small modulation, $\mathrm{n}_{1}=\mathrm{n}_{\mathrm{w}}+<(\mathrm{dn} / \mathrm{dc}) \mathrm{c}>+$ $(\mathrm{dn} / \mathrm{dc}) \delta \mathrm{c}$, where $\delta \mathrm{c}$ is the perturbation around the equilibrium concentration profile due to the AC potential at frequency, $\omega$. Generally, $\delta c=\delta c_{o} \cos (\omega t+\alpha)$, where $\delta c_{o}$ is the amplitude of the ion oscillation and $\alpha$ is the phase difference between the applied potential and the ion oscillation. The phase difference is primarily due to viscosity effects. The details of the constants and the composition of the solution is not as critical. The important aspect is the application of the AC potential the concentration oscillates. Thus, the optical property of the solution is,

$$
n_{1}=\left\langle n_{w}+\frac{d n}{d c} c\right\rangle+B \cos (\omega t+\alpha)
$$

where the first term in $\langle\ldots\rangle$ is a time-independent quantity that will change with $\mathrm{x}$ and is complex in the sense it depends on concentration profiles of various ionic species. $B$ is modified amplitude that includes $\delta c_{\circ}$ and the differential refractive index. As the interest is to measure change in $B$ as a function of applied ramp potential, $E$, the chemical details of $B$ are not critical.

By substituting Equation (3) in (1) and linearizing with only first order terms, i.e., no higher order harmonics, $2 \omega, 3 \omega$, and so on, the AC component of the reflectivity is,

$$
R=K+Q \delta c_{o}
$$

where $\mathrm{K}$ and $\mathrm{Q}$ are based on time-independent (i.e., equilibrium) optical properties of the solution and the electrode. Importantly, the differential reflectivity has a baseline (i.e., K) signal. The assumption of the linearity of the system is experimentally justified because the higher harmonics are over three orders of magnitude lower.

The principle is that at redox, due to discharge in the interfacial layer caused by electron exchange, the field penetration increases. As a result $\delta c_{o}$ increases during redox current. Thus, from Equation (4), the potential, E, where $\mathrm{R}$ is maximum, will coincide with where the current due to oxidation and reduction reaction is highest.

The typical oscillation of the amplitude of reflectivity $(R)$ at the detector (see Fig. 1(c)) as a function of periodic applied bias (E) on the WE with respect to the solution showed good periodicity with respect to E cycles (Fig. S5). A small portion of the scan is shown in Fig. 1(d). 


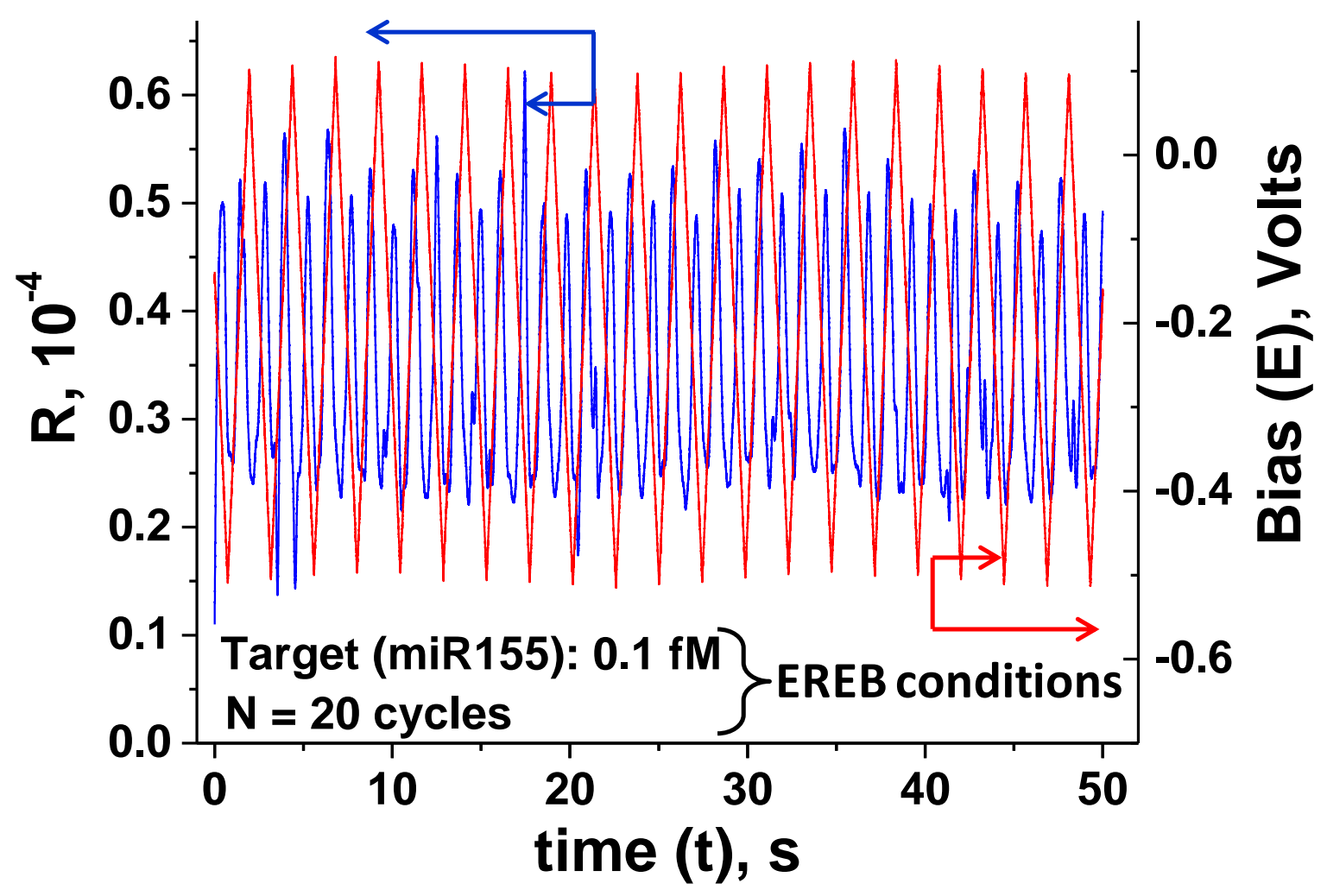

Figure S5: Typical scan of $R$ as a function of $t$ due to applied periodic potential $E(t)$.

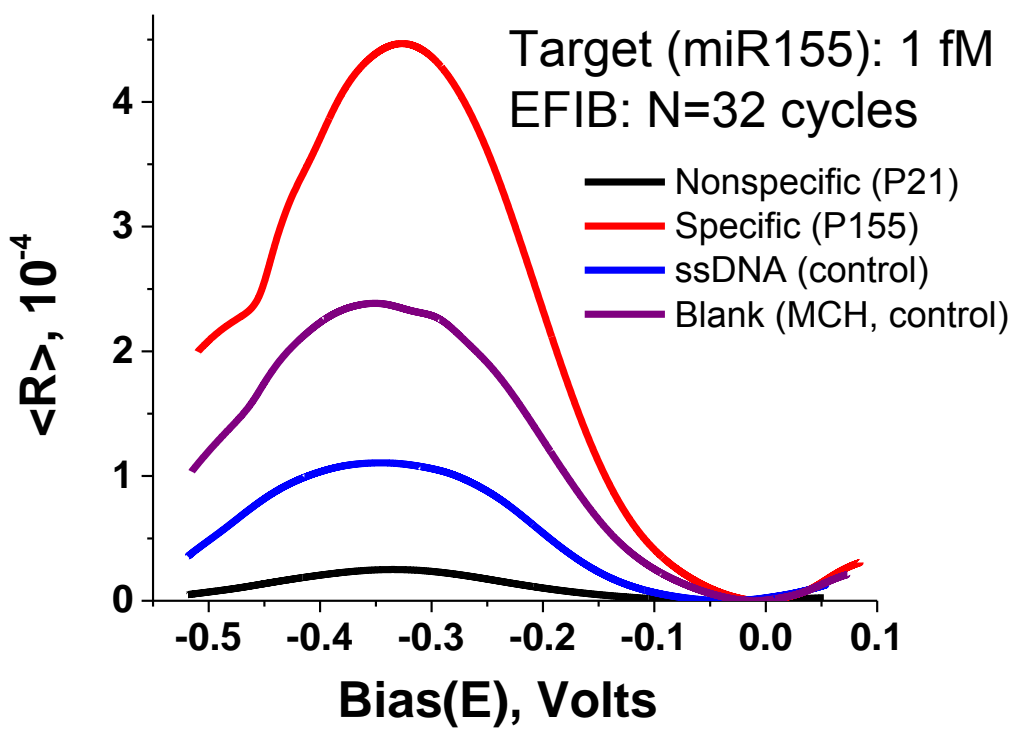

Figure S6: (a) Differential reflectivity from four spots when the $\mathrm{MCH}$ filling was not complete. The control (blank) shows complete $\mathrm{MCH}$ filling.

\section{S.6 Effect of Incomplete MCH Coverage}

Every chip was tested for quality of $\mathrm{MCH}$ coverage by measuring the signal on the three spots on the control electrode that were not subjected to EREB potential. The internal verification was critical to the quality of the data. The differential reflectivity 
measurement performed on the three sets of spots on the two control electrodes was blank (Au electrode coated with $\mathrm{MCH}$ ); the spot with P155 was filled with $\mathrm{MCH}$ (ssDNA); and the spot with P21 was filled with $\mathrm{MCH}$ (similar to ssDNA). In a chip with poor coverage, the blank and ssDNA show a peak due to MB redox due to pinholes (Fig. S6). As a result, the signal from a nonspecific spot was also positive indicating the specificity was not $100 \%$ (Fig. S6). Interestingly, the signal from a specific spot (i.e., spot with immobilized P155) was over threefold higher compared to the signal if the specificity was $100 \%$ (Fig. 2(a)) due to redox through the pinholes in the $\mathrm{MCH}$ monolayer. Such a chip was rejected for the study. The analysis on the control was performed for every chip prior to making the measurements on the five larger electrodes. A signal on the control spots will lead to poor specificity, and the specific signal would erroneously be considered over 3-fold higher. The spots with P155 and P21 probes on the control electrode showing no redox indicated that the signal was zero, if no binding occurred (i.e., ssDNA in Fig. 1(e)). Thus, the $\mathrm{R}_{\max }$ reported here is an absolute measurement of the amount of specific binding. $\mathrm{MCH}$ deposition was after EREB.

\section{S.7 Mixture Analysis}

A binary miRNA mixture was studied where the concentration of the nonspecific target, miR21, was $10^{3}$-fold larger. The effect of background miR21 showed that the signal for specific binding of miR155 was unchanged (Fig. S8). On the same chip with EFIB at $N=$ 20, 28, and 32 (Fig. S8, inset), for the pure miR155 target (first bar for each $\mathrm{N}$ ), the $\mathrm{R}_{\max }$ on the P21 spot was zero (hatched bar), indicating $100 \%$ specificity, while $R_{\max }$ on the P155 spot (solid bar) was consistent with the calibration in Fig. 2(b). For each N, the signal for miR155 on the P155 spot (solid bar) was constant irrespective of the amount of miR21, indicating no interference from the latter. The signal for the $1 \mathrm{pM} \mathrm{miR21} \mathrm{target}$ on the P21 spot (third hatch bar for each $\mathrm{N}$ ) was constant for all N, indicating saturation, as expected from Fig. 2(b).

For mixture analysis, a synthetic nonspecific probe sequence that did not match any of the known homo sapiens (hsa) mRNA sequences was used for the study. The sequence of the nonspecific probe was:

\section{5' ThioMC6-D/ GCA ATA ATG CTC TTT TTC AT 3'}

The sequences of the five background miRNA used for Fig. 3(a) were:

miR 145: 5' GTCCAGTTTTCCCAGGAATCCCT 3'

miR 29a: 5' ACTGATTTTCTTTTGGTGTTCAG 3'

miR 630: 5' AGTATTCTGTACCAGGGAAGGT 3'

miR 34a: 5' TGGCAGTGTCTTAGATGGTTGT 3'

miR 16-1: 5' TAGCAGCACGTAAAATATTGGCG 3'

Targets, miR155 (1 fM) and 21 (10 fM), were measured simultaneously in a background of these five miRNA each with a concentration of $1 \mathrm{pM}$. 


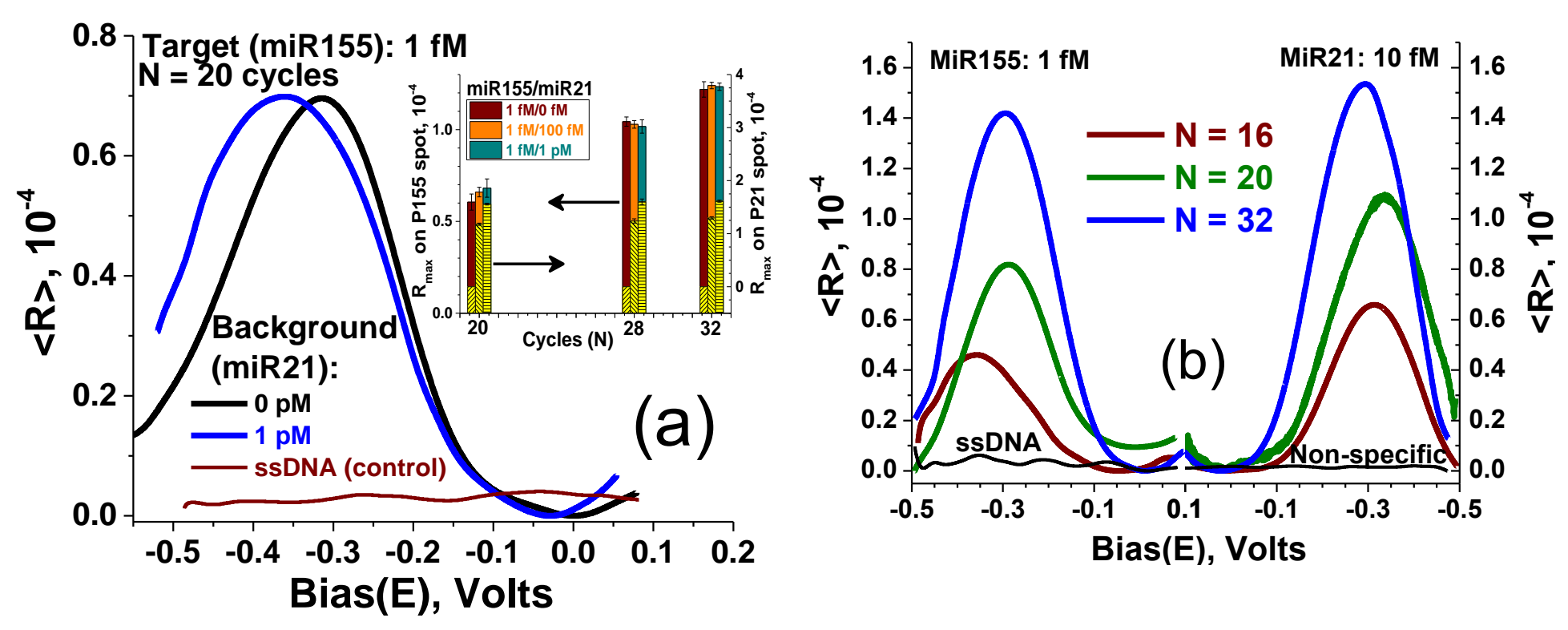

Figure S7: (a) Effect of background miR21 on $<R>$ as a function of $E$ on the same chip for specific binding to P155 and controls. Inset: A histogram of $R_{\max }$ for three chips measuring specific binding of a mixture to P155 and P21 spots. For each chip, EFIB was performed at three $\mathrm{N}$ each. The $\mathrm{R}_{\max }$ data for miR155 and mi21 targets were each averaged over 15 and 6 points, respectively. (b) Typical $\langle R>$ as function of $E$ on the same chip for specific binding to P155 and P21 spots and the controls.

\section{S.8 QPCR and SEED Analysis of miR39a for C. Elegans}

The standard curve was obtained by making solutions of known amount of synthetic ssRNA of $C$. elegans miR39a (IDT, Inc., USA) target in sterile DNase/RNase-free water (Invitrogen, USA). SYBR Green method (Clontech Lab., Inc) was adopted to perform the cDNA synthesis and qPCR measurements on the GPCR machine (QuantStudio 3 RT-PCR, ABI, USA). In brief, $3.75 \mu \mathrm{L}$ of a standard solution with known concentration was added to reverse transcriptase buffer and enzyme (the final reaction volume was $10 \mu \mathrm{L}$ ). The reaction was allowed to incubate at $37{ }^{\circ} \mathrm{C}$ for one hour, followed by denaturation of the RT enzyme at $85{ }^{\circ} \mathrm{C}$ for five minutes. The synthesized cDNA was diluted by 10 -fold. A $0.8 \mu \mathrm{L}$ portion was added to the master stock (SYBR Advantage Premix, ROX, miRNA-specific 5' and 3' primers) resulting in the final volume of $10 \mu \mathrm{L}$. Melting curves on qPCR products were also generated to confirm specificity of the amplification. After qPCR, the data was analyzed while setting the threshold fluorescence to 0.059 arbitrary units. The mean values of CT were plotted as a function number of copies provided for reverse transcription to synthesize the cDNA (Fig. S9). Thus, the CT value corresponds to the number of miR39a mixed in the $3.75 \mu \mathrm{L}$ solution. The standard curve was fit to the linear region of the semi-log plot. 


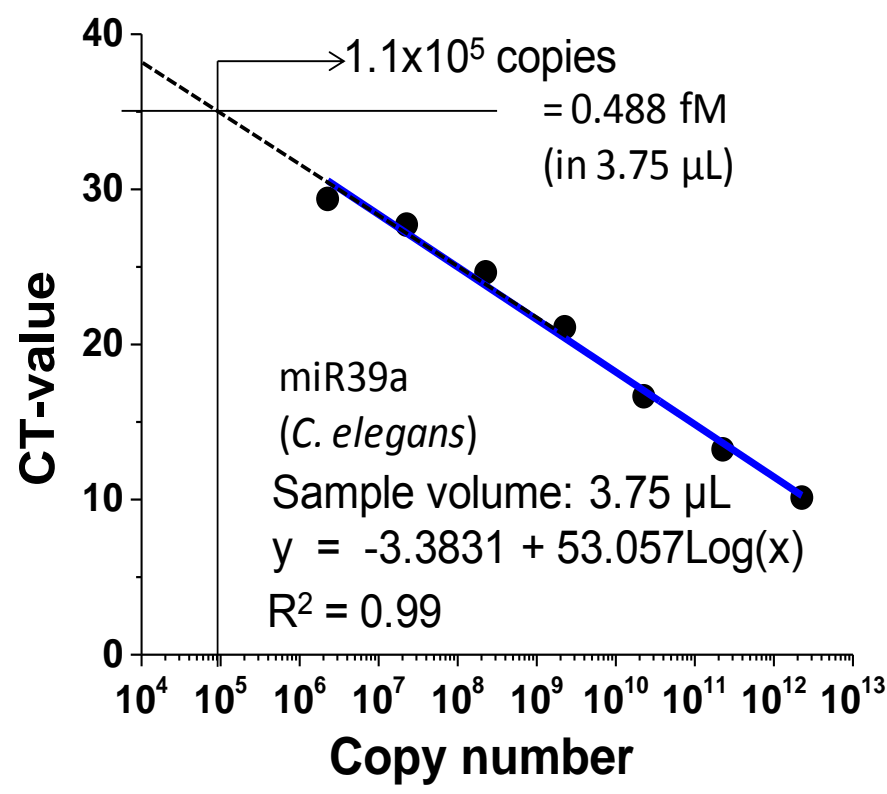

Figure S8: Standard curve of miR39a. The copy number is number of targer miRNA sequences in the RT-mix for cDNA conversion. Below $10^{6}$ number of copies the CT valu is too low for reliability and the curve becomes non-linear.

To demonstrate the sensitivity and specificity for a complex biological sample, about $\sim 14 \mu \mathrm{L}$ of total RNA was extracted from $\sim 200 \mu \mathrm{L}$ of plasma from a healthy human subjects using a standard kit (RNeasy plus kit from Qiagen). The sample was reconstituted in $300 \mu \mathrm{L}$ of PB buffer for EREB and spiked with synthetic miR39a of $C$. elegans at concentrations ranging from 0.01 to $10^{3} \mathrm{fM}$. No miR39a is present in the human plasma sample. As the A-tail ligation, cDNA conversion and qPCR steps are avoided, direct binding of the miRNA to ssDNA probe is performed at $4{ }^{\circ} \mathrm{C}$. For ssRNA (i.e., miRNA) as a target at low temperature, the EREB conditions are optimized to $0.4 \mathrm{~V}$ to $0.5 \mathrm{~V}$. $R_{\max }$ increases monotonically as the concentration of spiked miR39a increases, however, the signal is typically twofold larger than for ssDNA targets in Fig. $3(b)$. The signals from plasma (y-axis) and pure (x-axis) miR39a are literally identical along the $45^{\circ}$ line (Fig. 3(b), inset).

Further to demonstrate multiplexing, we detect the presence of four circulating miRNAs $(155,21,630$ and $34 a)$ in plasma and compare SEED results with QPCR. To precisely determine the accuracy of SEED signal conversion to the miRNA copies, we estimated $<$ Rmax $>$ based relative fold change for different miRNA in the normal and colorectalcancer patient plasma samples, and compared with the gold standard PCR. The known amount of miR-39a (C. elegance miR control) was spiked in eluted RNA solution to the final concentration of $1 \mathrm{pM}$. Aliquot of the spiked RNA from the same RNA samples was used to perform SEED and PCR so that both procedures start with the same solution to avoid any statistical inconsistencies.

We calculated the relative fold change of miRNA to 39 a using the following equations:

a) Relative fold change using PCR $\sim 2^{\Delta C t} \sim \frac{[\text { miRNA }]}{[39 a]}$

b) Relative fold change using SEED $\sim 2^{\log _{2}^{10}\left(\Delta R_{\max }\right)} \sim \frac{[\text { miRNA] }}{[39 a]}$

where, $[\ldots]$ is molar concentration, which is equivalent to copy number. 
Table: Comparative analysis of SEED and PCR based relative fold changes in multiple miRNAs of the normal and colorectal cancer patient plasma.

\begin{tabular}{|c|c|c|c|c|c|c|}
\hline \multirow[t]{2}{*}{ S.No. } & \multirow[t]{2}{*}{ Sequence } & \multicolumn{2}{|c|}{ SEED } & \multicolumn{2}{|c|}{ PCR } & \multirow[t]{2}{*}{ SEED/PCR } \\
\hline & & $\mathrm{R}_{\max }$ & $\begin{array}{l}\text { Fold change } \\
\text { relative to } \\
\text { miR-39a }\end{array}$ & Ct values & $\begin{array}{l}\text { Fold change } \\
\text { relative to } \\
\text { miR-39a }\end{array}$ & \\
\hline \multicolumn{7}{|c|}{ a) Normal Plasma } \\
\hline 1. & miR-21 & $3.14 \pm 0.26$ & $14.76 \pm 1.71$ & $22.03 \pm 0.48$ & $13.61 \pm 0.56$ & $1.09 \pm 0.14$ \\
\hline 2. & miR-34a & $2.13 \pm 0.33$ & $0.69 \pm 0.12$ & $25.29 \pm 0.28$ & $1.41 \pm 0.05$ & $0.49 \pm 0.09$ \\
\hline 3. & miR-155 & $0.88 \pm 0.19$ & $0.02 \pm 0.003$ & $29.66 \pm 0.32$ & $0.07 \pm 0.003$ & $0.22 \pm 0.05$ \\
\hline 4. & miR-630 & $0.76 \pm 0.23$ & $0.01 \pm 0.003$ & $31.71 \pm 0.13$ & $0.02 \pm 0.001$ & $0.63 \pm 0.20$ \\
\hline \multicolumn{7}{|c|}{ b) Patient Plasma } \\
\hline 1. & miR-21 & $3.77 \pm 0.26$ & $99.72 \pm 11.20$ & $19.07 \pm 0.75$ & $105.64 \pm 4.96$ & $0.94 \pm 0.12$ \\
\hline 2. & $\operatorname{miR}-34 a$ & $3.16 \pm 0.35$ & $15.80 \pm 2.22$ & $23.16 \pm 0.45$ & $6.20 \pm 0.19$ & $2.55 \pm 0.37$ \\
\hline 3. & miR-155 & $0.92 \pm 0.19$ & $0.02 \pm 0.003$ & $30.28 \pm 0.91$ & $0.04 \pm 0.002$ & $0.38 \pm 0.09$ \\
\hline 4. & miR-630 & $1.24 \pm 0.25$ & $0.04 \pm 0.009$ & $29.71 \pm 0.46$ & $0.07 \pm 0.002$ & $0.67 \pm 0.14$ \\
\hline
\end{tabular}

\section{References}

1. A. J. Bard and L. R. Faulkner, Electrochemical Methods: fundamentals and Applications (J. Wiley \& Sons, New York, 2001).

2. S. W. Lee, J. Lopez, and R. F. Saraf, Electroanalysis 25, 1557-1566 (2013).

3. I. Y. Wong and N. A. Melosh, Nano Letters 9, 3521-3526 (2009).

4. S. W. Lee, J. Lopez, and R. F. Saraf, Biosensors \& Bioelectronics 47, 408-414 (2013).

5. Z. L. Pei et al., Oncotarget 8, 22616-22624 (2017).

6. J. Tymoczko, et al. ACS Applied Materials \& Interfaces 6, 21851-21858 (2014). 